Bull. Chem. Soc. Ethiop. 2004, 18(1), 67-72.

Printed in Ethiopia

ISSN 1011-3924

(c) 2004 Chemical Society of Ethiopia

\title{
VARIATIONS OF THE FATTY ACID COMPOSITION IN THE OIL FROM THE LARVAL STAGES OF THE EMPEROR MOTH CATERPILLAR, IMBRASIA BELINA
}

\author{
M.T. Pharithi, S.M. Suping and S.O. Yeboah ${ }^{*}$ \\ Department of Chemistry, University of Botswana, Gaborone, Botswana
}

(Received May 26, 2003; revised August 19, 2003)

\begin{abstract}
The mophane caterpillar, phane, the larval stage of the emperor moth, Imbrasia belina, is an important food source, with increasing popularity, in the southern African region. The protein and fat contents of phane have been estimated as $55 \%$ and $33 \%(\mathrm{w} / \mathrm{w})$, respectively. Unsaturation content is about $60 \%$, with - -linolenic acid being the dominant fatty acid in the lipid content of phane. An earlier investigation showed that the iodine values of two oil samples from two batches of phane at different ages, i.e., instars, varied significantly. The proximate fatty acid composition has now been determined by capillary GC for five oil samples from five batches of mophane caterpillar, ranging between early III and late V instars in order to investigate any differences in the nature of the lipid content due to age. The oil yield increased steadily from $19.8 \%(\mathrm{w} / \mathrm{w})$ for early III instars to $38.3 \%$ for late V instars. The contents of palmitic and linoleic acids were $8.5 \%$ and $24 \%$, respectively, for early III instars, and $31.1 \%$ and $10.7 \%$, respectively, for late $\mathrm{V}$ instars. The composition of -linolenic acid peaked at $39.1 \%$ for III/IV instars but decreased to $32.5 \%$ for late $\mathrm{V}$ instars. The lipid content of the leaves of the mophane tree, the principal food source of the mophane caterpillar, was found to be composed of $24 \%$ palmitic acid, $4.1 \%$ palmitoleic acid, $5.6 \%$ stearic acid, $14.85 \%$ oleic acid, $15.6 \%$ linoleic acid and $32.9 \%$ linolenic acid, a fatty acid composition quite similar to that of mature phane, late $\mathrm{V}$ instars. Crude protein content varied irregularly with early III and late V instars being $59.3 \%$ and $62.0 \%(\mathrm{w} / \mathrm{w})$, respectively. This study has demonstrated a dramatic variation in the composition of palmitic and linoleic acids in the lipid content from early III to late V instars of the larvae of Imbrasia belina. The study has also confirmed the larvae of Imbrasia belina as a rich source of protein and --linolenic acid, the precursor of the $\omega 3$ essential fatty acids.
\end{abstract}

KEY WORDS: Crude protein, Instars, Larval stages, Imbrasia belina, Emperor moth, Mophane caterpillar, •-Linolenic acid, Phane, Variations of fatty acid composition

\section{INTRODUCTION}

The mophane caterpillar, mophane worm or phane (the most common local name), is the larval stage of the emperor moth, Imbrasia belina (Westwood) (Lepidoptera: Saturnnidae). The larvae of Imbrasia belina derive their local name, phane, from the mophane tree, Colophospermum mophane, whose leaves constitute the principal food source for the larvae. This larval stage goes through five developmental stages, instars; the $\mathrm{V}$ instars being the last stage before pupating.

Phane, which used to be a traditional food source to the people in the Northeastern district of Botswana, is now a cherished delicacy in the whole of Botswana and the surrounding countries, i.e., Namibia, South Africa and Zimbabwe. The mophane caterpillar has been reported to have outstanding nutritive properties, especially with regards to its protein and unsaturated fat content $[1,2]$. In an investigation of the nutritive values of phane, Sekhwela made a comparative study of the three principal constituents of food contained in phane, beef, biltong and chicken. The results showed that for $\mathrm{g} / 100 \mathrm{~g}$ of sample, phane had the highest content of protein $(56.8 \%)$, fat

${ }^{*}$ Corresponding author. Tel: 267-355 2496. Fax: 267-356591. E-mail: yeboahso@mopipi.ub.bw 
(16.4\%) and carbohydrate $(13.8 \%)$. This study underscored the high nutritional quality of the mophane worm [3].

In a preliminary quality evaluation of the oil from the mophane worm by this author, an appreciable difference in the iodine values was observed in the oils from mature phane (late $\mathrm{V}$ instars) and the oil from young phane (late IV/early V instars). A determination of the fatty acid composition of the two oil samples by capillary GC and NMR studies however showed that the two oil samples were in fact very similar [2]. It was however felt that the age difference between early $\mathrm{V}$ instars and late $\mathrm{V}$ instars phane was too close for any significant variations in their fatty acid composition to be observed. The present study was therefore conducted to determine the fatty acid composition of five oil samples from five batches of the mophane caterpillar between early III and late V instars in order to investigate any variations in the fatty acid composition that could be attributable to age difference. The crude protein content was also determined for each of the five batches of the mophane worm. In addition the fatty acid composition of the lipid content from the leaves of the mophane tree, $C$. mophane, was also determined to ascertain how the fatty acid profile of the mophane worm relates to the fatty acid composition of its food source.

\section{EXPERIMENTAL}

Materials. The larvae of the emperor moth, Imbrasia belina, of mixed ages were harvested from different locations in the Francistown area, in the Northeastern district of Botswana. The gut contents of the larvae were squeezed out in the normal fashion of preparing the larvae for food. The larvae were then stored under ethyl acetate to protect them from parasitoids. The larvae were later sorted and classified into five batches (labeled 1 to 5) according to their instars (early III to late V instars) using the graphical linear relationship between their head-capsule width and number of larval instars developed by Allotey et al. The results are as shown in Table 1 [4].

Table 1. Classification of the larvae of mophane caterpillar, into their developmental stages, instars [4].

\begin{tabular}{|l|l|l|}
\hline Batch & Head-capsule width $(\mathrm{mm})$ & Level of instars \\
\hline 1 & $3.10-3.35$ & III (early) \\
\hline 2 & $3.55-3.90$ & III (late) \\
\hline 3 & $5.30-5.50$ & III/IV \\
\hline 4 & $7.80-8.05$ & IV/V (early) \\
\hline 5 & $8.60-8.85$ & V (late) \\
\hline
\end{tabular}

Oil extraction. The five batches of larvae were dried in an oven at $50{ }^{\circ} \mathrm{C}$. Each category of phane was macerated in a Waring blender and the powder weighed and then extracted in a chloroform-methanol (2:1) solvent system by shaking on an orbital shaker (4 hours x 2). The resulting solution was evaporated off on a rotary evaporator and followed by a 'Folch-wash' to yield greenish-brown oil. The yields are as shown in Table 2.

Leaf-extract. Air-dried fresh leaves of the mophane tree, Colophospermum mophane, were ground into a powder (153 g) and extracted in the same way as for the mophane worms to give a green oily product. The lipid fraction was isolated by gradient elution on a silica gel column, using n-hexane $(100 \%)$, n-hexane:ether (8.2) and n-hexane: ether $(8: 2)$ solvent systems. The combined extracts were purified by dissolving in ether and drying the ether solution under anhydrous sodium sulphate to give an yellow oil $(18.7 \mathrm{~g}, 12.2 \%$, w/w).

Fatty acid composition: sample preparation. The oil samples were transesterified by refluxing in methanol that contained ethanoyl chloride to produce the fatty acid methyl esters (FAME) [5].

Bull. Chem. Soc. Ethiop. 2004, 18(1) 
Instrumentation and separation conditions. Fatty acid compositions were determined with a Perkin Elmer Autosystem Gas Chromatograph with on-column injection and flame ionization detection interfaced with a PE Nelson computer. The column was Omega Wax TM 320 capillary column [30 m x $0.32 \mathrm{~mm} \times 0.25 \mathrm{~mm}$ i.d. (Supelco Park, Bellefonse, PA, USA)]. The carrier gas was nitrogen at a pressure of $15.0 \mathrm{psi}$. The oven, injection and detection temperatures were fixed at 200, 250 and $260^{\circ} \mathrm{C}$, respectively. Reference compounds were standard FAME mixtures from Supelco and Sigma (Sigma Chemical Co., St Louis, MO, USA).

Nuclear magnetic resonance (NMR) analysis. Proton NMR spectra of the FAME's were acquired at $300 \mathrm{MHz}$ (acquisition parameters D1 and $\mathrm{AQ}=1.00 \mathrm{~s}$ and $5.31 \mathrm{~s}$, respectively) using a Bruker Avance DPX300 Spectrometer.

Protein content. The crude protein content for each sample of phane was determined by a semi automatic method using a Tecator, Buchi and Gerhardt instrumental Kjeldahl systems. Digestion was carried out in an electrically heated aluminium block digester, followed by distillation of ammonia into boric acid. Titration was then performed manually with $\mathrm{H}_{2} \mathrm{SO}_{4}$ $(0.05 \mathrm{M})$. The nitrogen content was multiplied by the factor 6.25 to obtain the crude percent protein contents shown in Table 2 [6].

Table 2. Percent oil yields $(\mathrm{w} / \mathrm{w})$ and protein content $(\mathrm{w} / \mathrm{w})$ from the larvae of mophane caterpillar at different instars.

\begin{tabular}{|c|l|c|c|c|c|}
\hline Batch & Instars & $\begin{array}{c}\text { Mass of } \\
\text { batch (g) }\end{array}$ & $\begin{array}{c}\text { Mass of oil } \\
\text { recovered }\end{array}$ & \% Yield (w/w) & $\begin{array}{c}\text { Protein content } \\
\%(w / w)\end{array}$ \\
\hline 1 & III early & 14.5 & 2.9 & 20.0 & 59.3 \\
\hline 2 & III late & 20.2 & 4.3 & 21.3 & 55.4 \\
\hline 3 & III/IV & 31.1 & 7.6 & 24.5 & 59.1 \\
\hline 4 & IV/V (early) & 23.8 & 9.1 & 38.2 & 41.7 \\
\hline 5 & V (late) & 43.9 & 16.9 & 38.5 & 62.0 \\
\hline
\end{tabular}

Except for the classification of the larvae into instars, all experiments were performed in duplicate and the results are expressed as the mean.

\section{RESULTS AND DISCUSSION}

The pattern of oil yields from the five batches of the mophane caterpillar found in this work is consistent with the earlier finding that a direct correlation existed between percent yield of oil and size, i.e., age of the larvae of Imbrasia belina [2]. Thus Table 2 shows a regular increase in oil yield from batch $1(20.0 \%$, w/w) (early III instars) to batch $5(38.5 \%$, w/w) (late V instars).

The crude protein content of a corresponding set of five batches of the mophane worm was determined in order to verify the validity of the data often quoted in the literature [3]. It is very clear from Table 2 that the mophane caterpillar is indeed a rich source of protein. Even though Table 2 does not show any particular pattern of variation in the crude protein content of the various instars, the average crude protein content determined in this work was $55.4 \%(\mathrm{w} / \mathrm{w})$, a figure quite close to Sekhwela's finding (56.8\%) [3].

The determination of the fatty acid composition of the lipid content of the five larvae batches of Imbrasia belina was, as indicated earlier, prompted by the earlier work in which oils from two larvae batch samples, very close in age, were investigated and were shown to have 
essentially the same composition even though their iodine values (IV) were significantly different [2]. The two crucial findings in the previous study were that (a) the percent ratio of total unsaturated fatty acid to total saturated fatty acids was 57\%:40\%, and (b) the single most abundant fatty acid in the lipid content of the larvae of Imbrasia belina was $\alpha$-linolenic acid, 18:3 n-3, (29\%). The results of the present investigation are shown in Table 3, which shows that the two important findings of the previous study are firmly upheld by the results of the present study in which the total composition of unsaturated fatty acids range from a maximum of $69.3 \%$ at early III instars to a minimum of $58.1 \%$ at late $\mathrm{V}$ instars. The average unsaturated fatty acid content over the range of the five oil samples investigated was $66.8 \%$. It is worth noting that the unsaturated fatty acid content of $58.1 \%$ found for late $\mathrm{V}$ instars in this study is quite consistent with the value of $57 \%$ for late $\mathrm{V}$ instars found in the previous work [2].

Table 3. Fatty acid composition (\% w/w) of the lipid content of the larvae of the mophane caterpillar at different instars as estimated by capillary GC.

\begin{tabular}{|c|c|c|c|c|c|}
\hline Fatty acids & $\begin{array}{c}\text { Batch 1 } \\
\text { III (early) } \\
\text { instars }\end{array}$ & $\begin{array}{c}\text { Batch 2 } \\
\text { III (late) } \\
\text { instars }\end{array}$ & $\begin{array}{c}\text { Batch 3 } \\
\text { III/IV } \\
\text { instars }\end{array}$ & $\begin{array}{c}\text { Batch 4 } \\
\text { IV/V (early) } \\
\text { instars }\end{array}$ & $\begin{array}{c}\text { Batch 5 } \\
\text { V (late) } \\
\text { instars }\end{array}$ \\
\hline $16: 0$ & 8.5 & 14.3 & 12.3 & 11.1 & 30.1 \\
\hline $18: 0$ & 14.5 & 14.3 & 13.3 & 15.0 & 10.7 \\
\hline $18: 1 \mathrm{n}-9$ & 10.4 & 9.7 & 12.2 & 10.1 & 14.8 \\
\hline $18: 2 \mathrm{n}-6$ & 24.5 & 24.2 & 19.7 & 23.8 & 10.7 \\
\hline $18: 3 \mathrm{n}-3$ & 34.3 & 33.5 & 39.1 & 34.2 & 32.5 \\
\hline Unknowns & 7.8 & 4.0 & 3.4 & 5.8 & 1.2 \\
\hline Total & 100 & 100 & 100 & 100 & 100 \\
\hline Saturation & 23.0 & 28.6 & 25.6 & 26.1 & 40.8 \\
\hline Unsaturation & 69.2 & 67.4 & 71 & 68.1 & 58.0 \\
\hline
\end{tabular}

The variations of the fatty acid composition of the lipid content among the different instars of the mophane caterpillar showed two major but opposite trends as can be observed in Table 3 . There is a gentle but non-regular variation of the palmitic acid, 16:0, content between early III instars (batch 1) and IV instars (batch 4) with an average composition of 11.6\%. However at late $\mathrm{V}$ instars the palmitic acid content suddenly increased to $30.1 \%$, a value that compares quite well with the palmitic acid content of $27.2 \%$ found for late $\mathrm{V}$ instars in the earlier investigation [2]. The content of linoleic acid, 18:2 n-6, on the other hand showed the opposite trend in its variation. The content of linoleic acid remained fairly stable between early III instars to IV instars with an average composition of $32.1 \%$, and then suddenly dropped to $10.7 \%$ at late $\mathrm{V}$ instars. It is again worth noting that the linoleic acid composition estimated in the earlier work for late $\mathrm{V}$ instars was $11.5 \%$ [2].

The variations in the composition of stearic, 18:0, oleic, 18:1 n-9, and $\alpha$-linolenic acids among the different instars were less drastic than those of palmitic and linoleic acids. From Table 3, whilst the composition of stearic acid drops in an irregular fashion from $14.5 \%$ for early III instars to $10.7 \%$ for late V instars, the composition of oleic acid gently increases, again in a staggered way, from $10.5 \%$ for early III instars to $14.8 \%$ for late V instars. The content of $\alpha$-linolenic acid peaked at $39.1 \%$ for late III/early IV instars (batch 3) but decreased between IV/early V instars $(34.3 \%)$ and late V instars (32\%).

Table 4 shows the fatty acid profile of the oil fraction from the leaves of the mophane tree as determined by capillary GC and also estimated from proton NMR integrals in the olefinic region [2]. The composition of saturated, monounsaturated and diunsaturated fatty acids can be

Bull. Chem. Soc. Ethiop. 2004, 18(1) 
estimated by comparing the integrals of signals from olefinic ( $c a 5.2 \mathrm{ppm}$ ), allylic ( $c a 2.02 \mathrm{ppm}$ ) and bis-allylic ( $c a 2.76 \mathrm{ppm}$ ) protons and relating them to the ${ }^{1} \mathrm{H}$ signal from the methyl group ( $c a 0.85 \mathrm{ppm}$ ). The $\mathrm{n}-3$ fatty acids are estimated by comparing the methyl triplet at $0.98 \mathrm{ppm}$ with the methyl group at $0.85 \mathrm{ppm}$. The NMR analysis rather exaggerated the monounsaturation content. However in general the proton NMR analysis corroborated the capillary GC results. Comparing Tables 3 and 4 it can be observed that the total unsaturated fatty acid composition in the C. mophane leaves $(68.4 \%)$ is more similar to that in early III instars than in the late V instars larvae. The palmitic acid content in the leaves, on the other hand, is closer to the late $\mathrm{V}$ instars than in the early III instars. In general the fatty acid profile of the lipid fraction from the mophane leaves is strikingly similar to the average fatty acid composition of the lipid content in the mophane caterpillar. The protein-energy ratio of the mophane leaves has been determined to be about $8.1 \mathrm{mg} / \mathrm{kJ}$, which points to the good quality diet of the mophane caterpillar [7]. There is thus a good correlation between the nutritional value of the mophane worm and the quality of the food it feeds on.

Table 4. Fatty acid composition of the lipid content of the leaves of mophane tree as estimated by capillary $\mathrm{GC}$ and from ${ }^{1} \mathrm{H}$ NMR integrals.

\begin{tabular}{|c|c|c|}
\hline Fatty acid & \% Composition by GC & $\begin{array}{c}\text { Fatty acid classes estimated from } \\
{ }^{1} \text { H NMR integrals \% by mole }\end{array}$ \\
\hline $16: 0$ & 24.5 & \\
$18: 0$ & 5.5 & \\
$20: 0$ & 1.6 & 36.3 \\
Total saturation & 31.6 & Monounsaturation \\
\hline $16: 1 \mathrm{n}-7$ & 4.9 & 25.4 \\
$18: 1 \mathrm{n}-9$ & 14.9 & Diunsaturation \\
& & 10.4 \\
$18: 2(\mathrm{n}-6)$ & 15.6 & 27.9 \\
$18.3(\mathrm{n}-3)$ & 33.0 & 63.7 \\
Total unsaturation & 68.4 & \\
\hline
\end{tabular}

The present study has demonstrated that variations in the fatty acid composition of the lipid content of the larvae of the mophane worm, I. belina, occur as the larvae go through the various developmental stages. In particular, the study has shown that the early instars of the larvae contain more linoleic acid and less palmitic acid than is the case of the mature larvae, where the compositions of linoleic and palmitic acids are in the reverse order. Variations in fatty acids content during maturation of organisms have been observed in the plant kingdom, where changes in the fatty acids content during maturation of soybean seeds was observed to occur between twenty-five and sixty days before leveling off. In this case the contents of palmitic, stearic and linolenic acids decreased, whilst contents of oleic and linoleic acids increased [8]. To the best of our knowledge this paper constitutes the first report of a variation in the fatty acids content in the larvae of an insect. It will be interesting to study the lipid biochemistry that causes such changes in the early stages of these organisms.

This study has once again demonstrated that the mophane worm is a rich source of $\alpha$-linolenic acid, the precursor of the $\omega 3$ essential fatty acids. Thus the consuming populations of the mophane worm benefit from the widely acclaimed health protecting properties of the $\omega 3$ polyunsaturated fatty acids (PUFA [9, 10]. 


\section{REFERENCES}

1. van Voorthuizen, E.G. Botswana Notes and Records 1976, 8, 233.

2. Yeboah, S.O.; Motshegwe, S.M.; Holmback. J. J. Am. Oil Chem. Soc. 1998, 75, 725.

3. Sekhwela, M.B.M. Botswana Notes and Records 1989, 20, 151.

4. Allotey, J.; Mpuchane, S.F.; Siame, A.B.; Gashe, B.A.; Teferra. G. Biological Studies of the Mophane Worm, Imbrasia belina, Under Laboratory Conditions, Proceedings of the First Multidisciplinary Symposium on Phane, Department of Biological Sciences, University of Botswana, Botswana, 1996, pp. 71-75.

5. Christie, W.W. Lipid Analysis, Pergamont Press: Oxford, England; 1982; pp. 52-53.

6. Ronald, S.K.; Sawyer, R. Pearson's Composition and Analysis of Foods, 9th Ed., Longman Scientific Technical: Harlow, England; 1991; pp.16-21.

7. Teferra, G.; Allotey, J.; Mpuchane, S.F.; Siame, A.B.; Gashe, B.A. The Nutrient Composition of the leaves of Colophospermum mophane and Sclerocarya bierrea and their Quality Food for Mophane Worms, Proceedings of the First Multidisciplinary Symposium on Phane, Department of Biological Sciences, University of Botswana, Botswana, 1996; pp. 69-70.

8. Rubel, A.; Rinne, R.W.; Cavin, D.T. Crop Sci. 1972, 12, 739.

9. Arne, Nordoy; Marchioli, R.; Arnesen, H.; Videbraek, J. Lipids 2001, 36, Supplement, S127.

10. Sinclair, A.J.; Attarbashi, N.M.; Duo, Li Lipids 2002, 37, 1113. 